Supplement of Hydrol. Earth Syst. Sci., 24, 3737-3752, 2020

https://doi.org/10.5194/hess-24-3737-2020-supplement

(c) Author(s) 2020. This work is distributed under

the Creative Commons Attribution 4.0 License.

(c) (1)

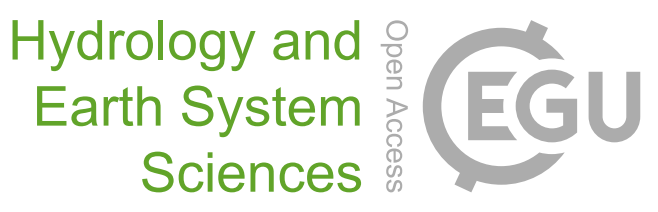

Supplement of

\title{
Using water stable isotopes to understand evaporation, moisture stress, and re-wetting in catchment forest and grassland soils of the summer drought of 2018
}

Lukas Kleine et al.

Correspondence to: Lukas Kleine (l.kleine@igb-berlin.de)

The copyright of individual parts of the supplement might differ from the CC BY 4.0 License. 

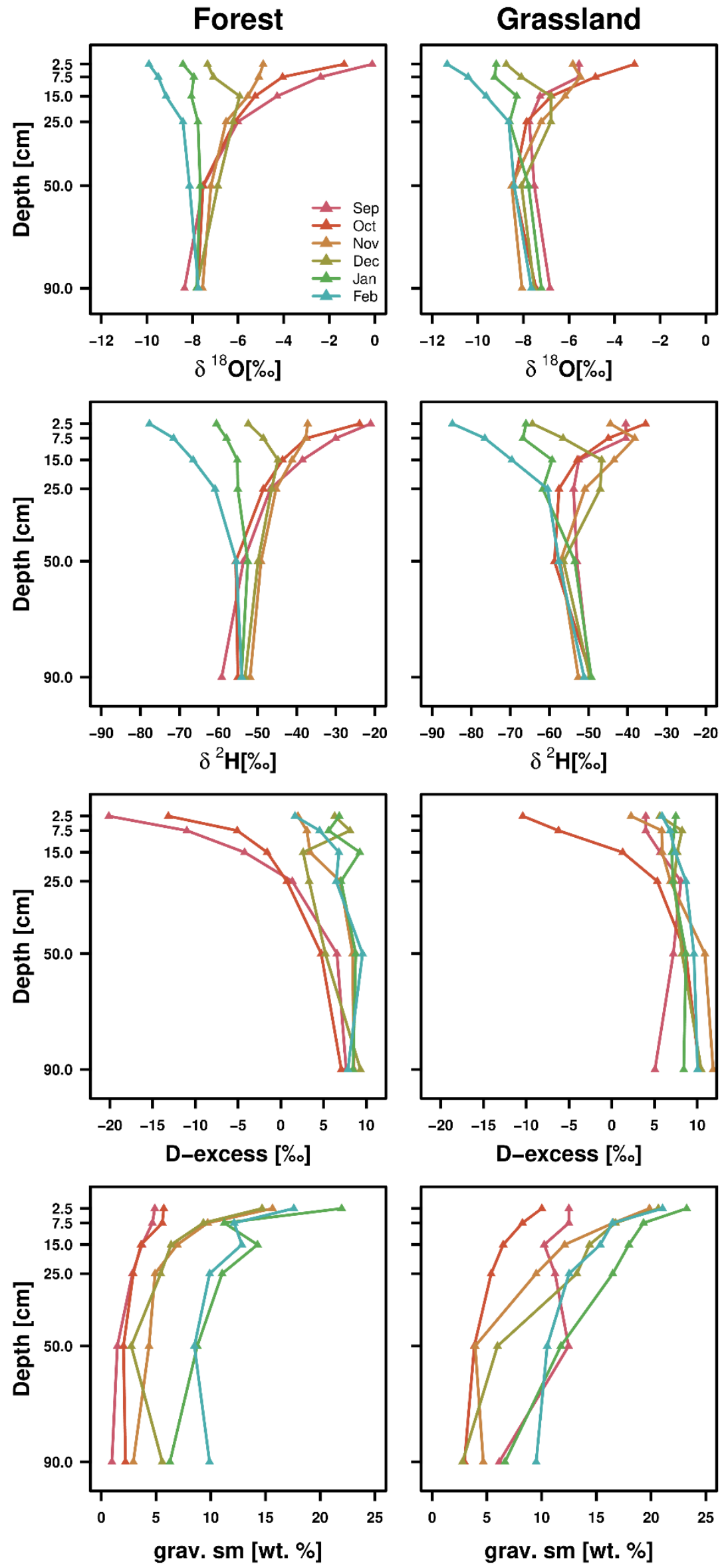

Figure S1. Soil profiles of water stable isotope $\delta$-values, d-excess and gravimetric soil moisture at the forested (left) and grassland (right) site. 